\title{
Prediction of Neck Dissection Requirement After Definitive Radiotherapy for Head and Neck Squamous Cell Carcinoma
}

\author{
Juliette Thariat, M.D. ${ }^{1,2}$, K. Kian Ang, M.D., Ph.D. ${ }^{1}$, Pamela K. Allen, PhD. ${ }^{1}$, Anesa Ahamad, \\ M.D. ${ }^{1,3}$, Michelle D. Williams, M.D., M.D. ${ }^{4}$, Jeffrey N. Myers, M.D, Ph.D. ${ }^{5,8}$, Adel K. El- \\ Naggar, M.D., Ph.D. ${ }^{4}$, Lawrence E. Ginsberg, M.D. ${ }^{6}$, David I. Rosenthal, M.D. ${ }^{1}$, Bonnie S. \\ Glisson, M.D. ${ }^{7}$, William H. Morrison, M.D. ${ }^{1}$, Randal S. Weber, M.D. ${ }^{4}$, and Adam S. Garden, \\ M.D. ${ }^{1, *}$ \\ ${ }^{1}$ Department of Radiation Oncology, University of Texas M. D. Anderson Cancer Center, 1515 \\ Holcombe Blvd. Houston, TX 77030, Texas \\ ${ }^{2}$ Department of Radiation Oncology/IBDC CNRS UMR 6543. Cancer Center Antoine- \\ Lacassagne. University Nice Sophia-Antipolis. 33 Av. Valombrose. 06189 - NICE Cedex 2 \\ (FRANCE) \\ ${ }^{3}$ The University of the West Indies, St. Augustine, Trinidad and Tobago \\ ${ }^{4}$ Department of Pathology, University of Texas M. D. Anderson Cancer Center, 1515 Holcombe \\ Blvd. Houston, TX 77030, Texas \\ ${ }^{5}$ Department of Head and Neck Surgery, University of Texas M. D. Anderson Cancer Center, \\ 1515 Holcombe Blvd. Houston, TX 77030, Texas
}

${ }^{6}$ Department of Diagnostic Radiology, University of Texas M. D. Anderson Cancer Center, 1515 Holcombe Blvd. Houston, TX 77030, Texas

${ }^{7}$ Department of Thoracic/Head and Neck Medicine, University of Texas M. D. Anderson Cancer Center, 1515 Holcombe Blvd. Houston, TX 77030, Texas

${ }^{8}$ Department of Cancer Biology, University of Texas M.D. Anderson Cancer Center, 1515 Holcombe Blvd. Houston, TX 77030, Texas

\footnotetext{
Abstract

(C) 2011 Elsevier Inc. All rights reserved.

"CORRESPONDING AUTHOR: GARDEN A.S., Department of Radiation Oncology-Unit 97, University of Texas M. D. Anderson, Cancer Center, 1515 Holcombe Blvd. Houston, TX 77030, Texas, Phone: (713) 563-2300, Fax: (713) 563-2366, Adam S. Garden (agarden@mdanderson.org).

MEETING PRESENTATION:

Presented at the $48^{\text {th }}$ annual meeting of the American Society of Radiation Oncology (ASTRO), November 6-9, 2006, Philadelphia, PA, US.

Presented at the $48^{\text {th }}$ annual meeting of the American Society of Clinical Oncology (ASCO), June 4-7, 2010, Chicago, IL, US.

CONFLICT OF INTEREST NOTIFICATION: The authors declare no conflict of interest

Publisher's Disclaimer: This is a PDF file of an unedited manuscript that has been accepted for publication. As a service to our customers we are providing this early version of the manuscript. The manuscript will undergo copyediting, typesetting, and review of the resulting proof before it is published in its final citable form. Please note that during the production process errors may be discovered which could affect the content, and all legal disclaimers that apply to the journal pertain.
} 
BACKGROUND-This analysis was undertaken to assess the need for planned neck dissection in patients with a complete response (CR) of involved nodes after irradiation, and to determine the benefit of a neck dissection in those with less than CR by tumor site.

METHODS-Our cohort included 880 patients with T1-4, N1-3M0 squamous cell carcinoma of the oropharynx, larynx or hypopharynx who received treatment between 1994 and 2004. Survival curves were calculated by the Kaplan-Meier Method, comparisons of rates with the log-rank test and prognostic factors by Cox analyses.

RESULTS-Nodal CR occurred in 377 (43\%) patients of whom 365 patients did not undergo nodal dissection. The 5-year actuarial regional control rate of patients with CR was $92 \%$. Two hundred sixty-eight of the remaining patients (53\%) underwent neck dissections. The 5-year actuarial regional control rate for patients without a CR was $84 \%$. Those who had a neck dissection fared better with 5-year actuarial regional control rates of $90 \%$ and $76 \%$ for those operated and those not operated $(\mathrm{p}<.001)$. Variables associated with poorer regional control rates included higher $\mathrm{T}$ and $\mathrm{N}$ stage, non-oropharynx cancers, non-CR, both clinical and pathological.

CONCLUSIONS-With 92\% 5-year neck control rate without neck dissection after CR, there is little justification for systematic neck dissection. The addition of a neck dissection resulted in higher neck control after partial response though patients with viable tumor on pathology specimens had poorer outcomes. The identification of that subgroup that benefits from additional treatment remains a challenge.

\section{Keywords}

Head and Neck Cancer; Neck nodes; Neck Dissection; Radiation therapy

\section{INTRODUCTION}

Many patients with locally advanced pharyngeal and laryngeal cancers are currently being treated with definitive radiation with or without chemotherapy with surgery reserved for removal of residual disease. However, the view that nodal disease might be more radioresistant than the primary tumor ${ }^{1}$ has led to controversy on the necessity of a planned neck dissection following radiation for patients presenting with advanced nodal disease. This controversy is best demonstrated in the design of Phase III trials during the past two decades, as some organ preservation trials mandated post-radiation neck dissections, while others left the decision of whether to surgically treat the neck at the discretion of the treating physicians. ${ }^{2-10}$

There is general agreement that patients with less than complete response (CR) should undergo neck dissection to eliminate potential residual viable tumor cells in the nodes ${ }^{11,12}$. It has also been accepted that patients with $\mathrm{CR}$ of $\mathrm{N} 1$ disease do not require neck dissection ${ }^{3,4}$. The controversy is principally centered over whether a clinical CR predicts eradication of N2-3 disease. No randomized clinical trial has yet specifically addressed the need to perform a neck dissection in the subset of patients with CR after radiotherapy.

We have been advocating for observation following CR of nodal disease irrespective of the initial nodal extent. In 1996, we described our experience in 62 node positive patients with 
oropharyngeal cancer who were treated with concomitant boost radiation and observed following complete response ${ }^{2}$. The isolated neck failure rate was less than 5\% suggesting observation was safe in patients with nodal CR. In addition to suggesting that observation of patients with a CR is safe, we recommended confirming a CR with imaging. This current study was undertaken to validate our post-radiotherapy neck dissection policy and establish recommendations on whether to perform a neck dissection in some patient subsets depending on post-radiotherapy clinical and pathologic response ${ }^{13,14}$. We began this current study from the time point that the prior study was completed and included patients with larynx and hypopharynx cancers to determine whether findings from oropharynx cancer are also applicable in other squamous cell cancers of the head and neck.

\section{MATERIAL/METHODS}

The medical records of patients with squamous cell carcinoma of the oropharynx, hypopharynx or larynx receiving definitive radiotherapy at The University of Texas M. D. Anderson Cancer Center from January 1994 through June 2004 were reviewed retrospectively upon obtaining approval from the Institutional Review Board. Patients undergoing neck dissections or excision of nodal disease prior to radiation were excluded.

\section{Staging}

The disease was staged according to the 2002 AJCC TNM classification ( $6^{\text {th }}$ edition ${ }^{15}$. We used radiographic $\mathrm{N}$ stage when disagreement existed between clinical and radiographic $\mathrm{CT}$ based initial $\mathrm{N}$ stage.

\section{Treatment modalities}

All new patients were discussed at tumor board by the multidisciplinary team and treatment decisions were made collegially. Radiotherapy was delivered either with conventional or altered (twice-daily or concomitant boost) fractionation, consistent with our previously reported policy. ${ }^{16}$ The dose to the nodes was not intentionally limited in view of a planned neck dissection.

Our general policy was not to dissect the neck in patients with CR. However, the multidisciplinary team responsible for the patient made the ultimate decisions regarding neck dissection. PET-CT was not used, as this reported experience predates the routine use of PET-CT. Some physicians chose to use ultrasound as a complementary procedure to assist with decision making. ${ }^{17}$ In addition to response, the patients' medical conditions were factored into the decision making.

\section{Assessment of Response}

Patients underwent physical examination and contrast-enhanced computerized tomography (CT) of the head and neck, four to eight weeks after radiotherapy. A complete response (CR) was defined as no palpable tumor on physical examination and no evidence of disease on radiographic examination. CT interpretation was based on nodal size, shape, ring enhancement, overall density and areas of central low density, border regularity and neatness/signs of extra-capsular spread. Patients who did not achieve a CR were analyzed 
together, but also evaluated as 3 separate subgroups, i.e., 1) patients with $<50 \%$ response, no response or progression (NR), 2) patients with $250 \%$ ) response on physical examination and CT (PR), and 3) patients with an equivocal CR. This latter group included patients without palpable disease, but CT evidence of nodal remnants that could not conclusively be called non-malignant.

\section{Pathologic response in post- radiotherapy neck nodes}

In the absence of an international grading system for pathological criteria for assessing the response to radiotherapy in the nodes, we grouped the findings into presence or absence of residual viable tumor (any identifiable quantity, microscopic or macroscopic) as reported by pathologists.

\section{Study Endpoints}

Neck control-Planned neck dissection was considered a component of the multimodality treatment, and as such was not considered failure. Post-radiotherapy neck failures were defined as the reappearance of nodal tumor after complete disappearance $(+/-$ neck dissection) of metastatic nodes or as unresectable neck disease after radiotherapy. Isolated neck failure was defined as recurrence of tumor in the neck with primary disease control.

\section{Statistical methods}

All time-to-failure endpoints were calculated from the date of completion of radiotherapy. Differences of distributions of patient, disease and treatment characteristics were tested by the Pearson chi $^{2}$ test. Differences in mean values for continuous variables were performed with either ANOVA or the student t-test. Regional control rates were estimated using the Kaplan-Meier method and compared with the logrank test. These statistical tests were performed with the assistance of SPSS statistical software application (v12.0).

The Cox's proportional hazard model was used for multivariate analysis to assess the effect of patient characteristics and other prognostic factors of significance on the end points. All variables with a significance of 0.25 or less on univariate analysis were entered into the model and backwards elimination carried out. The final model consisted of variables with a significance value of $\leq 0.05$. The estimated hazard is reported. The Wald test was used to assess the role of covariates in the model. These statistical tests were performed using Stata (Release 11.0, StataCorp LP).

\section{RESULTS}

\section{Patient and disease characteristics}

Eight hundred eighty patients formed the study cohort. Patient and disease characteristics are detailed in Table 1. The most common nodal stages were N2b (40\%) and N2c (26\%), though only $32 \%$ of patients had a node greater than $3 \mathrm{~cm}$. Median follow-up for living patients was 51 months (range 0-143). Only 14 surviving patients (2\%) had less than 24-month followup. 


\section{Treatment modalities}

Table 2 summarizes treatment characteristics, which reflects our policy of delivering high radiation dose to involved nodes. Fractionation schedules had changed during the study period and intensity modulated radiotherapy (IMRT) was introduced later mostly for the treatment of patients with oropharyngeal carcinoma. More than half the patients received systemic therapy. The median radiation dose to both the primary tumor and nodes was 70 Gy.

\section{Response to (Chemo)radiotherapy and subsequent management of the neck}

Response of nodal disease was both clinically and radiographically complete in 377 patients (43\%), partial in $490(56 \%)$ or progressive in $13(1 \%)$. Among partial responders, $232 \mathrm{had}$ an equivocal remnant and 258 had clear residual masses of $<50 \%$ of the original size. Nodal size post-radiotherapy was greater than $1.5 \mathrm{~cm}$ in 186 patients $(21 \%)$.

Two hundred sixty-eight patients (30\%) underwent neck dissection (Table 2). The median time from the completion of radiation to the performance of a neck dissection was 62 days. Twenty-three patients had their neck dissections delayed for more than 100 days following radiation completion.

Two hundred forty-two patients had ipsilateral neck dissections, and 26 patients underwent bilateral dissections. There were 23 radical neck dissections, 56 modified radical dissections and 215 selective dissections. ${ }^{18}$ Neck dissection specimens harbored viable tumor in 80 patients (30\%); 35 patients (46\%) with radical or modified radical dissections had viable disease, while 45 patients (23\%) who underwent selective dissections had viable disease. Distribution of viable tumor by primary site was $50 \%, 54 \%$ and $25 \%$ respectively for hypopharyngeal, laryngeal, and oropharyngeal cancers.

The response to (chemo)radiotherapy highly influenced the decision to perform neck dissection ( $\mathrm{p}$ <.001). Twelve patients $(3 \%)$ underwent neck dissections after CR to radiotherapy, principally due to participation on protocol. Only one patient $(8 \%)$ had viable tumor in the neck dissection specimen.

Decisions to perform neck dissections in patients without CR were individualized. Eightysix patients were not amenable to surgery due to co-morbidities, treatment toxicity, or unresectable/progressive disease. Excluding these 86 patients, all but 7 of 185 patients who had both palpable masses and radiographic evidence of less than complete response underwent neck dissection. Viable tumor was detected in 54 patients of these patients (30\%). Seventy-eight patients (33\%) with an equivocal complete response underwent neck dissections, and viable tumor was detected in 25 (31\%).

\section{Nodal Control}

Overall, 105 patients (12\%) had nodal relapse. A flow chart demonstrating nodal relapse based on response and neck dissection is displayed in Figure 1. The actuarial 2- and 5-year regional control rates were $89 \%$ and $87 \%$, respectively. However, only $30(4 \%)$ patients had isolated regional recurrences, i.e., without recurrence at the primary site. So, the actuarial 2 - 
and 5-year regional control rates in patients without primary tumor relapse were $97 \%$ and $96 \%$, respectively.

\section{Prognostic factors for neck control}

Adverse prognostic factors for neck control are detailed in Tables 3 and 4. Among pretreatment univariate variables, higher nodal stage, larger nodes, involvement of multiple nodal levels, fixation and extra-capsular extension were all associated with nodal relapse. Additional variables associated with nodal relapse included advanced T-stage and primary site as there were fewer failures in patients with oropharynx cancers compared to larynx or hypopharynx. T-stage, $\mathrm{N}$-stage (specifically $\mathrm{N} 3 \mathrm{vs} \mathrm{N} 1$ ) and primary site remained significant in multivariate analysis. Fixation and extra-capsular extension were excluded from the model due to numerous missing values.

No treatment variable was associated with increased nodal failures in multivariate analysis. Induction therapy was significant in univariate analysis but was highly correlated with other adverse features, including hypopharyngeal primaries and more advanced nodal disease. Evaluating the entire cohort, nodal control rates were similar in the group with neck dissection (90\%) compared to the group who did not have surgery (87\%, p=.48). However, in the subgroup of patients with less than a CR, those undergoing a neck dissection had a higher regional control rate $(90 \%$ versus $76 \%$ at 5 years, $p<0.001)$ (Figure 2), regardless of the primary response.

The extent of response was associated with nodal control. The five-year regional control rate was $92 \%$ in patients with a complete response compared to $83 \%$ in patients without a complete response $(\mathrm{p}<0.001)$. For patients with less than a complete response, the extent of response was also associated with regional control, as the 5-year regional control rates in patients with equivocal CR, PR and NR were $86 \%, 82 \%$ and $50 \%$, respectively. Nodal size post-radiation was also associated with nodal relapse. A persistent node greater than $3 \mathrm{~cm}$ in size was uncommon, occurring in less than $4 \%$ of patients, but the crude nodal recurrence rate in this situation was $48 \%$.

Pathologic response was also associated with nodal recurrence, as the 5-year actuarial nodal control rate for patients with viable tumor in the specimen was 75\% compared to $96 \%$ for those without viable disease (Figure 3). Patients with less than a CR and viable tumor removed did not have better neck control than those with less than $\mathrm{CR}$ who did not undergo neck dissection.

Primary tumor relapse was also associated with nodal recurrence. The 5-year actuarial regional control rate was $96 \%$ in patients with local control versus $63 \%$ in patients with recurrence at the primary site $(\mathrm{p}<.001)$

\section{Nodal Control by primary site}

The actuarial 5-year regional control rates were $90 \%$ for oropharyngeal cancers, $84 \%$ for laryngeal cancers and $78 \%$ for hypopharyngeal cancers ( $\mathrm{p}<.001$ ). Regional control rates varied by nodal stage within each site. 
Patients with hypopharyngeal cancer and with nodes over $3 \mathrm{~cm}$ had greater than $35 \%$ isolated and overall neck recurrences at 5 years. Among 8 patients with N3 disease, none had a CR, and 4 of 6 recurred in the neck despite primary disease control.

Patients with oropharyngeal disease with nodes greater than $3 \mathrm{~cm}$ had an overall nodal relapse rate of $4 \%$. Five-year neck control and isolated neck control in oropharyngeal cancer patients with N3 disease was lower than in other nodal stage subgroups (72\%). However, all 11 patients with $\mathrm{N} 3$ disease that recurred in the neck had fixed nodes, and 7 of these patients also had recurrences at the primary site. The crude isolated and overall neck recurrence rates for patients with oropharynx cancer and N3 disease were $14 \%$ and $40 \%$, respectively. Necrotic or cystic nodes were less likely to be complete responders and larger nodes were more often necrotic or cystic.

\section{Nodal control by nodal size}

Two-hundred eighty (32\%) patients presented with at least one node greater than $3 \mathrm{~cm}$ in size. Seventy-nine (28\%) had a CR, and only 3 of these patients (4\%) had disease recur in the neck. Among patients with an equivocal CR, the crude neck recurrence rate was $15 \%$ both among patients who did or did not have neck dissections. However, among the remaining patients without a $\mathrm{CR}$, the neck recurrence rates were $12 \%$ for those who underwent a neck dissection versus $40 \%$ for those who did not.

\section{DISCUSSION}

The results of our current study confirm that our policy of selecting patients based on response of their disease resulted in high rates of nodal control. The capacity of a clinical and radiological CR to predict neck control was excellent with a negative predictive value of $96 \%$ in nearly four hundred patients. These findings are consistent with earlier reports from our institution evaluating this strategy in oropharyngeal patients treated with either concomitant boost radiation ${ }^{2}$, or induction chemotherapy followed by radiation. ${ }^{19}$

Historically, the assessment of nodal response following radiotherapy has been based on physical examination performed from four to eight weeks after completion of radiotherapy ${ }^{4,8,20}$. CT-based algorithms were developed for more accurate assessment of the response to radiotherapy ${ }^{21-23}$ and in the 1990's and early 2000's physical examination and post-contrast CT were combined to assess the "clinical" response to (chemo)radiotherapy. The improvements in response assessment led some to switch from performing planned neck dissections in all node-positive patients to a strategy of dissecting only patients with a complete response at the primary and incomplete response in the neck. In 1986, the team from the University of Florida described their approach of planned neck dissection for all patients. ${ }^{24}$ Twenty years later, they published their experience of using CT criteria for decision-making. They did not detect any difference in outcomes in their patients with clinical and CT complete responses who either underwent neck dissections or did not, and thus advocated a policy of dissecting only if patients did not have complete responses. ${ }^{22}$ Similarly, the group from the University of Chicago switched their recommendations, as in 2000 , they advocated planned neck dissection for all patients regardless of response ${ }^{8}$, but in 2009 advocated neck dissection only for those patients with residual nodes on CT following 
chemoradiation. ${ }^{25}$ The Trans Tasman Radiation Oncology Group adapted a policy of observation for patients with $\mathrm{N} 2-\mathrm{N} 3$ disease enrolled on their randomized trial evaluating the role of Tirapazamine, and reported no isolated neck failure without a planned neck dissection. ${ }^{26}$ In our study, complete clinical responders could avoid a neck dissection, as the overall negative predictive value of physical exam and CT was $96 \%$. Thus, $43 \%$ of all our patients, $39 \%$ of those staged N2-3 and $28 \%$ of those with nodes greater than $3 \mathrm{~cm}$ were adequately assessed by physical examination and $\mathrm{CT}$ alone. The positive predictive value of this approach though was only $18 \%$. The overall regional control rate for patients undergoing neck dissection was high, but only $30 \%$ of patients had viable tumor. Patients with viable tumor in their neck dissections had poorer prognoses, not only with respect to regional control, but to all disease outcome measures.

Numerous groups have investigated other imaging modalities to better select patients for neck dissection. PET-CT is currently advocated as the imaging modality of choice. ${ }^{27,28}$ Retrospective studies report high negative predictive values and moderately high positive predictive values ranging from $60-90 \% .{ }^{29-31}$ Our team recently reported a prospective trial evaluating the utility of PET-CT compared to CT. ${ }^{32}$ In that trial, the overall positive predictive value was not much better for PET-CT compared to CT. However, subset analysis suggested that PET-CT may be more useful in high-risk patients, defined as those arising from non-oropharyngeal sites, human papillomavirus negative tumors, and tumors arising in smokers and alcohol users. In these settings, the positive predictive value of PET-CT rose to $75 \%$. Sher and colleagues have reported that PET-CT, while roughly 5 times the cost of CT appears to be a more cost-effective strategy for determining the need for neck dissection. ${ }^{33}$ While using Markov models, the group only analyzed PET-CT versus CT. Based on our experiences, it appears that $\mathrm{CT}$ can be used as an initial screening tool at $6-8$ weeks, with PET-CT done 6 weeks later and reserved for patients with positive findings, especially those considered at high risk.

Noteworthy, this series mostly consisted of oropharyngeal cancers, which have previously been assessed at our institution and described by Peters et al. ${ }^{2}$ and Clayman et al. ${ }^{19}$ It was noted in this current series that five-year actuarial regional control rates indeed varied by primary site. The 5-year actuarial regional control rates were over $90 \%$ for patients with oropharyngeal cancers and were extremely high for patients with $\mathrm{N} 2$ disease and nodes greater than $3 \mathrm{~cm}$ but smaller than $6 \mathrm{~cm}$. Patients with laryngeal and hypopharyngeal cancers fared worse, especially those patients presenting with more advanced primary and/or nodal disease. The worst outcomes were seen in patients with hypopharyngeal primary tumors and N3 nodal disease, as no patient had a CR and only half of the patients were able to undergo a neck dissection. Based on our series, further data are needed to determine if the hypopharyngeal group with nodes over $3 \mathrm{~cm}$ would benefit more from systematic upfront neck dissection than neck dissection in partial responders.

While neck dissection remains a recommended treatment for those patients without complete response, those patients who are found to have viable disease in our study had poorer prognoses. Effective strategies to address this need to be developed. Currently, our approach has been to consider adjuvant systemic therapy, but this strategy has not been proven. 
In conclusion, observing patients with complete response in the neck after (chemo)radiation appears safe from an oncologic perspective, as few complete responders develop regional relapse. While neck dissections are relatively safe surgical procedures, they do potentially add to the morbidity of chemoradiation. ${ }^{34,35}$ Our large series provides addition evidence 27,36 that planned neck dissections are not required in all node positive patients undergoing chemoradiation.

\section{Acknowledgments}

This work was supported partly by grants P01 CA06294 awarded by the National health Institute, Lavoisier awarded by the French Ministry of Foreign Affairs, supplemented by the Philip Foundation and the Gilbert H. Fletcher Memorial Distinguished Chair.

\section{References}

1. Wolf GT, Fisher SG. Effectiveness of salvage neck dissection for advanced regional metastases when induction chemotherapy and radiation are used for organ preservation. Laryngoscope. 1992; 102:934-9. [PubMed: 1495357]

2. Peters LJ, Weber RS, Morrison WH, et al. Neck surgery in patients with primary oropharyngeal cancer treated by radiotherapy. Head Neck. 1996; 18:552-9. [PubMed: 8902569]

3. Brizel DM, Prosnitz RG, Hunter S, et al. Necessity for adjuvant neck dissection in setting of concurrent chemoradiation for advanced head-and-neck cancer. Int J Radiat Oncol Biol Phys. 2004; 58:1418-23. [PubMed: 15050318]

4. Lavertu P, Adelstein DJ, Saxton JP, et al. Management of the neck in a randomized trial comparing concurrent chemotherapy and radiotherapy with radiotherapy alone in resectable stage III and IV squamous cell head and neck cancer. Head Neck. 1997; 19:559-66. [PubMed: 9323143]

5. Robbins KT, Atkinson JL, Byers RM, et al. The use and misuse of neck dissection for head and neck cancer. J Am Coll Surg. 2001; 193:91-102. [PubMed: 11442259]

6. Robbins KT, Wong FS, Kumar P, et al. Efficacy of targeted chemoradiation and planned selective neck dissection to control bulky nodal disease in advanced head and neck cancer. Arch Otolaryngol Head Neck Surg. 1999; 125:670-5. [PubMed: 10367925]

7. Sanguineti G, Corvo R, Benasso M, et al. Management of the neck after alternating chemoradiotherapy for advanced head and neck cancer. Head Neck. 1999; 21:223-8. [PubMed: 10208665]

8. Stenson KM, Haraf DJ, Pelzer H, et al. The role of cervical lymphadenectomy after aggressive concomitant chemoradiotherapy: the feasibility of selective neck dissection. Arch Otolaryngol Head Neck Surg. 2000; 126:950-6. [PubMed: 10922226]

9. Weisman RA, Christen RD, Jones VE, et al. Observations on control of N2 and N3 neck disease in squamous cell carcinoma of the head and neck by intra-arterial chemoradiation. Laryngoscope. 1998; 108:800-5. [PubMed: 9628492]

10. Weisman RA, Robbins KT. Management of the neck in patients with head and neck cancer treated by concurrent chemotherapy and radiation. Otolaryngol Clin North Am. 1998; 31:773-84. [PubMed: 9735106]

11. Simon C, Goepfert H, Rosenthal DI, et al. Presence of malignant tumor cells in persistent neck disease after radiotherapy for advanced squamous cell carcinoma of the oropharynx is associated with poor survival. Eur Arch Otorhinolaryngol. 2006; 263:313-8. [PubMed: 16328403]

12. Robbins KT, Doweck I, Samant S, et al. Effectiveness of superselective and selective neck dissection for advanced nodal metastases after chemoradiation. Arch Otolaryngol Head Neck Surg. 2005; 131:965-9. [PubMed: 16301367]

13. Thariat J, Ahamad A, Garden AS, et al. Prediction of Neck Dissection (ND) Requirement Following Definitive Radiotherapy (RT) for Head And Neck Squamous Cell Carcinoma (HNSCC). Int J Radiat Oncol Biol Phys. 2006; 66:S17-S18. 
14. Thariat J, Hamoir M, Janot F, et al. Neck dissection following chemoradiation for node positive head and neck carcinomas. Cancer Radiother. 2009

15. AJCC. Manual for staging of cancer. 6. 2002.

16. Ang, K.; Garden, A. Radiotherapy for Head and Neck Cancers: Indications and Techniques. 3. Philadelphia, PA: Lippincott Williams \& Wilkins; 2005.

17. Yom S, Garden A, Staerkel G, et al. Ultrasound Examination of the Neck after Definitive Radiotherapy for Node-Positive Oropharyngeal Cancer. AJNR. 2011 In press.

18. Robbins K, Clayman G, Levine P, et al. Neck Dissection Classification Update. Arch Otolaryngol Head Neck Surg. 2002; 128:751- 758. [PubMed: 12117328]

19. Clayman GL, Johnson CJ 2nd, Morrison W, et al. The role of neck dissection after chemoradiotherapy for oropharyngeal cancer with advanced nodal disease. Arch Otolaryngol Head Neck Surg. 2001; 127:135-9. [PubMed: 11177029]

20. Newman JP, Terris DJ, Pinto HA, et al. Surgical morbidity of neck dissection after chemoradiotherapy in advanced head and neck cancer. Ann Otol Rhinol Laryngol. 1997; 106:11722. [PubMed: 9041815]

21. Merritt RM, Williams MF, James TH, et al. Detection of cervival metastasis. A meta-analysis comparing computed tomography with physical exmaination. Arch Otolaryngol Head Neck Surg. 1997; 123:149-52. [PubMed: 9046281]

22. Liauw SL, Mancuso AA, Amdur RJ, et al. Postradiotherapy neck dissection for lymph nodepositive head and neck cancer: the use of computed tomography to manage the neck. J Clin Oncol. 2006; 24:1421-7. [PubMed: 16549836]

23. Vergeer MR, Doornaert P, Leemans CR, et al. Control of nodal metastases in squamous cell head and neck cancer treated by radiation therapy or chemoradiation. Radiother Oncol. 2006; 79:39-44. [PubMed: 16632006]

24. Mendenhall WM, Million RR, Cassisi NJ. Squamous cell carcinoma of the head and neck treated with radiation therapy: the role of neck dissection for clinically positive neck nodes. Int J Radiat Oncol Biol Phys. 1986; 12:733-40. [PubMed: 3710857]

25. Langerman A, Plein C, Vokes EE, et al. Neck response to chemoradiotherapy: complete radiographic response correlates with pathologic complete response in locoregionally advanced head and neck cancer. Arch Otolaryngol Head Neck Surg. 2009; 135:1133-6. [PubMed: 19917927]

26. Corry J, Peters L, Fisher R, et al. N2-N3 neck nodal control without planned neck dissection for clinical/radiologic complete responders - results of Trans Tasman Radiation Oncology Study 98.02. Head Neck. 2008; 30:737- 742. [PubMed: 18286488]

27. Ferlito A, Corry J, Silver CE, et al. Planned neck dissection for patients with complete response to chemoradiotherapy: a concept approaching obsolescence. Head Neck. 2010; 32:253-61. [PubMed: 19572281]

28. Schöder H, Fury M, Lee N, et al. PET monitoring of therapy response in head and neck squamous cell carcinoma. J Nucl Med. 2009; 50:74S- 88S. [PubMed: 19380408]

29. Connell CA, Corry J, Milner AD, et al. Clinical impact of, and prognostic stratification by, F-18 FDG PET/CT in head and neck mucosal squamous cell carcinoma. Head Neck. 2007; 29:986-95. [PubMed: 17563906]

30. Porceddu SV, Jarmolowski E, Hicks RJ, et al. Utility of positron emission tomography for the detection of disease in residual neck nodes after (chemo)radiotherapy in head and neck cancer. Head Neck. 2005; 27:175-81. [PubMed: 15627258]

31. Yao M, Graham MM, Smith RB, et al. Value of FDG PET in assessment of treatment response and surveillance in head-and-neck cancer patients after intensity modulated radiation treatment: a preliminary report. Int J Radiat Oncol Biol Phys. 2004; 60:1410-8. [PubMed: 15590172]

32. Moeller BJ, Rana V, Cannon BA, et al. Prospective risk-adjusted [18F]Fluorodeoxyglucose positron emission tomography and computed tomography assessment of radiation response in head and neck cancer. J Clin Oncol. 2009; 27:2509-15. [PubMed: 19332725]

33. Sher DJ, Tishler RB, Annino D, et al. Cost-effectiveness of CT and PET-CT for determining the need for adjuvant neck dissection in locally advanced head and neck cancer. Ann Oncol. 2009 
34. Lango M, Myers J, Garden ASRO. Controversies in surgical management of the node-positive neck after chemoradiation. Semin Radiat Oncol. 2009; 19:24-28. [PubMed: 19028342]

35. Machtay M, Moughan J, Trotti A, et al. Factors associated with severe late toxicity after concurrent chemoradiation for locally advanced head and neck cancer: an RTOG analysis. J Clin Oncol. 2008; 26:3582-3589. 2008. [PubMed: 18559875]

36. Vedrine PO, Thariat J, Hitier M, et al. Need for neck dissection after radiochemotherapy? A study of the French GETTEC Group. Laryngoscope. 2008; 118:1775-80. [PubMed: 18806474] 


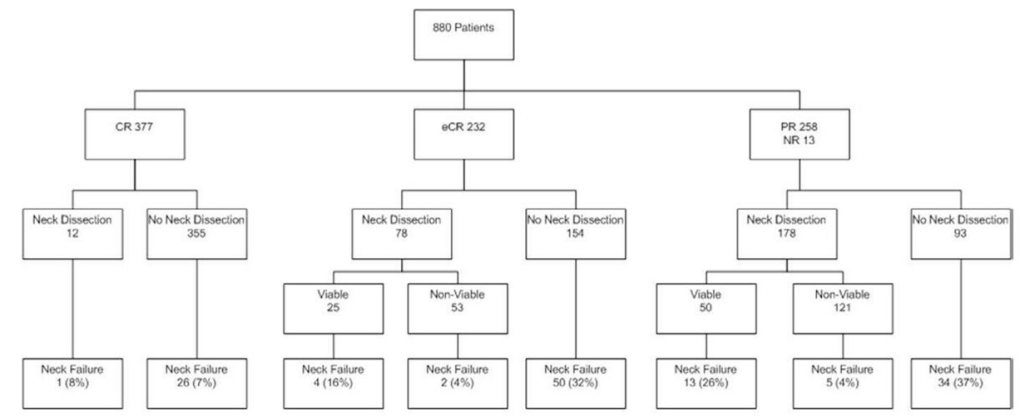

Figure 1.

Flow chart outlining responses, neck dissections and crude neck failure rates in our cohort of 880 patients (CR - complete response; eCR - equivocal CR; PR - partial response; NR less than PR). 


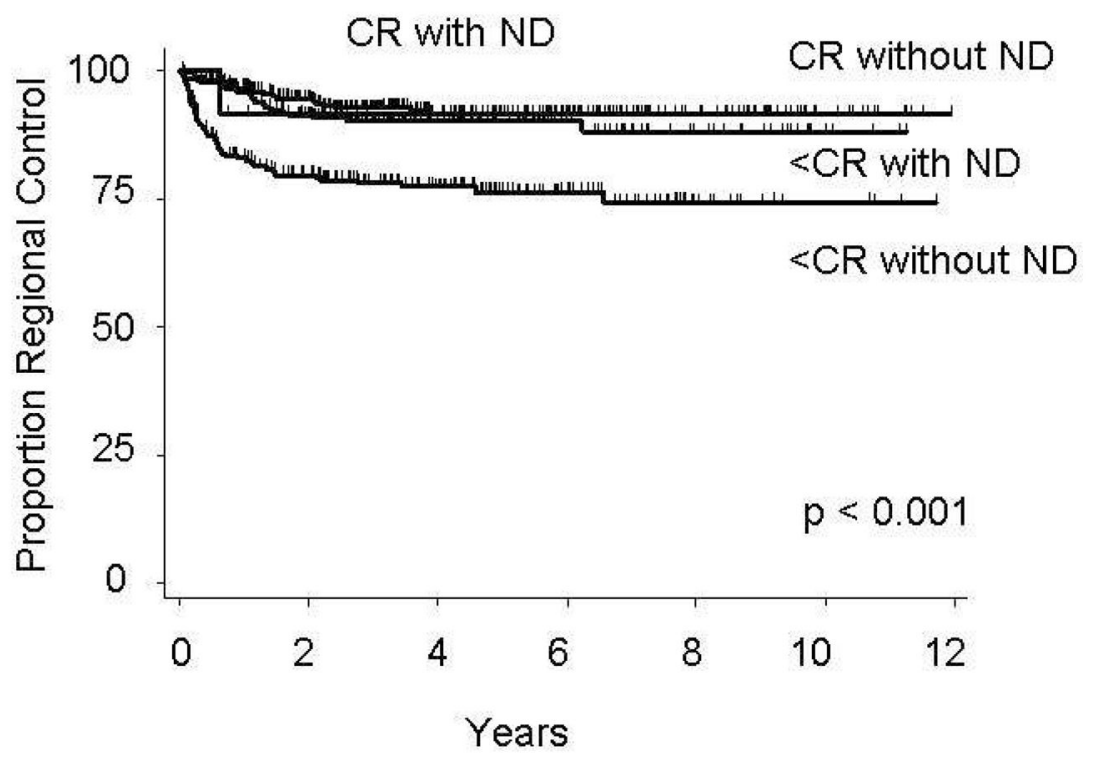

Figure 2.

Regional control by neck dissection (ND) and complete response (CR) 


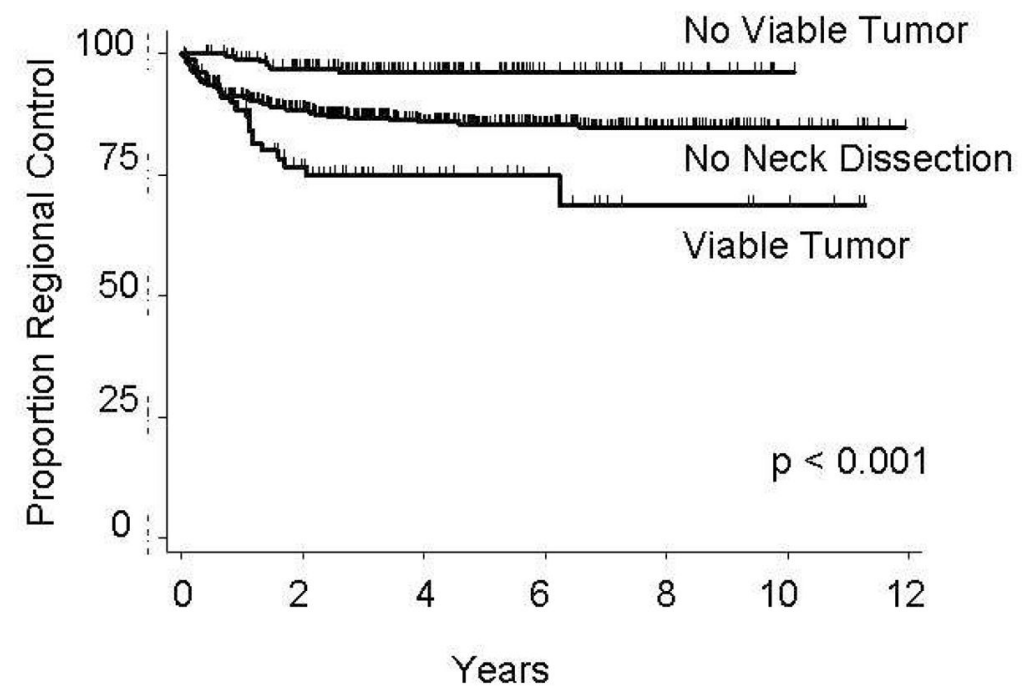

Figure 3.

Regional control by neck dissection and pathological response 


\begin{tabular}{|c|c|c|c|c|c|c|c|c|c|c|c|c|c|c|c|c|c|c|c|c|c|c|}
\hline 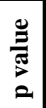 & & $\stackrel{0}{0}$ & $\begin{array}{l}\overline{8} \\
\dot{8} \\
\dot{v}\end{array}$ & $\begin{array}{l}\overline{8} \\
\dot{\theta} \\
v\end{array}$ & & & & $\stackrel{\infty}{\circ}$ & & & & & 守 & & & $\tilde{z}$ & $\tilde{z}$ & $\begin{array}{l}\vec{b} \\
0 \\
0\end{array}$ & $\stackrel{0}{0}$ & 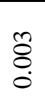 & & \\
\hline 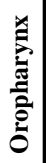 & $\begin{array}{l}\text { o } \\
\text { E } \\
\text { है } \\
\text { II }\end{array}$ & $\stackrel{\infty}{\infty}$ & 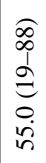 & $\stackrel{Ð 0}{\cong}$ & 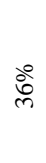 & 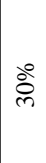 & : & ঐ̊ & 80 & $\stackrel{\stackrel{\Im}{~}}{ }$ & $\stackrel{\stackrel{\circ}{+}}{\sim}$ & 80 & 官 & $\stackrel{\stackrel{0}{\infty}}{\stackrel{n}{n}}$ & $\stackrel{\stackrel{ }{\simeq}}{ }$ & $\stackrel{\circ}{\stackrel{0}{ }}$ & $\frac{8}{6}$ & 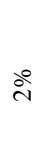 & $\frac{\stackrel{\circ}{+}}{\mathrm{m}}$ & 官 & $\stackrel{\stackrel{\Im}{\sim}}{\stackrel{y}{2}}$ & $\stackrel{\infty}{\infty}$ \\
\hline
\end{tabular}

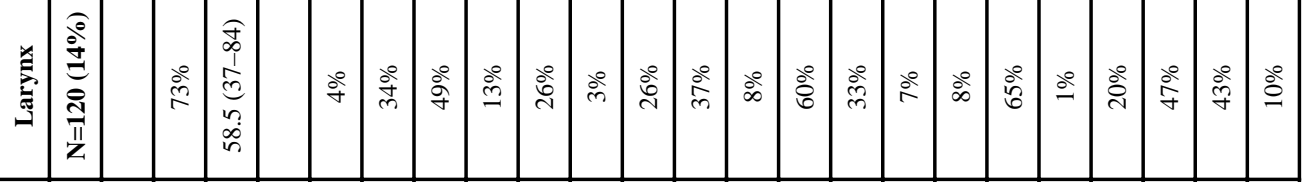

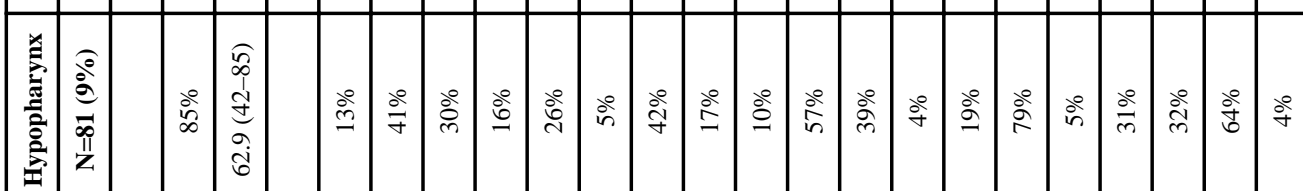

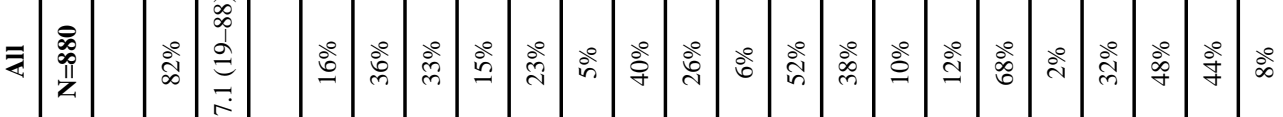

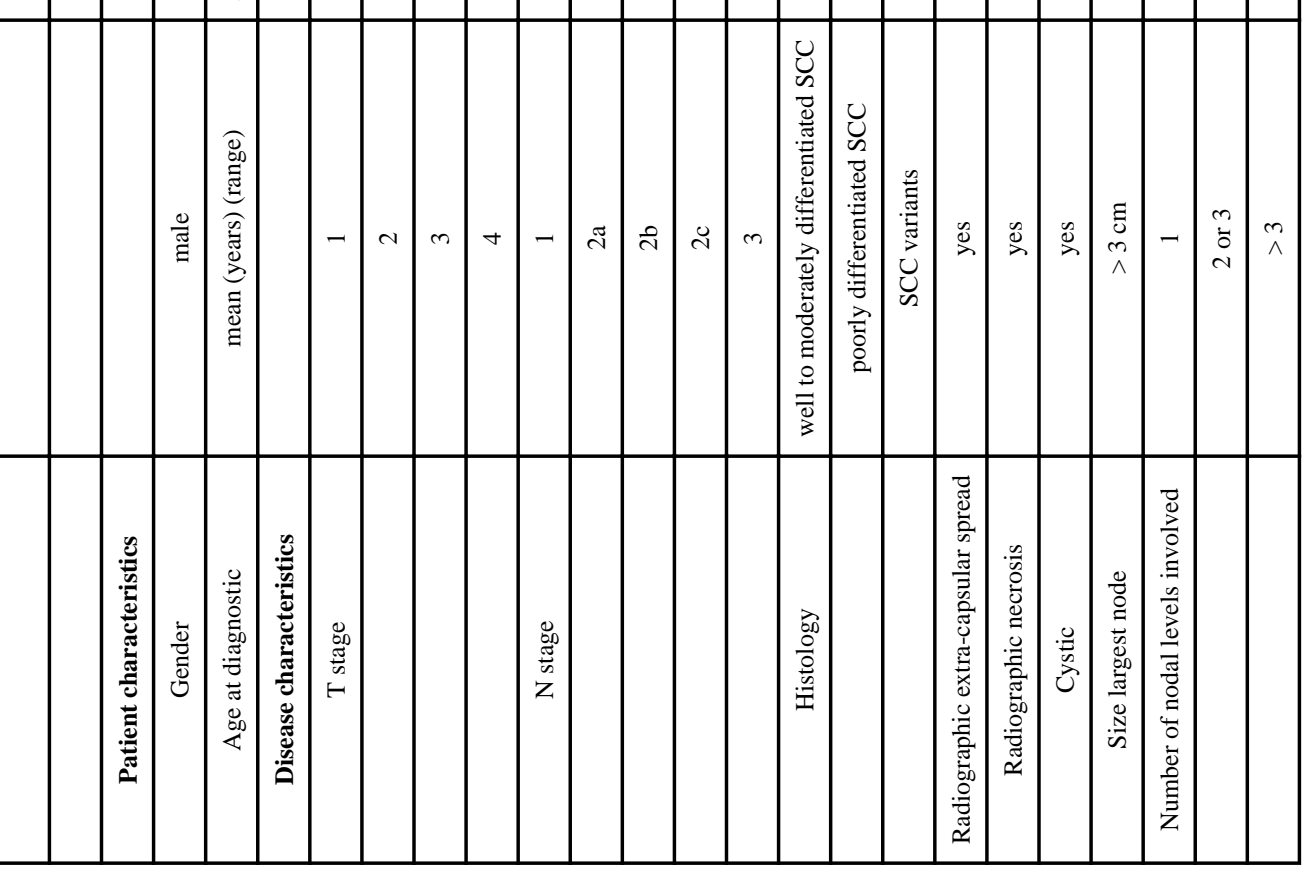

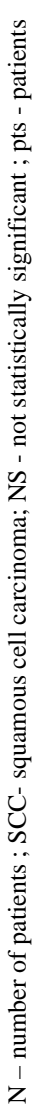




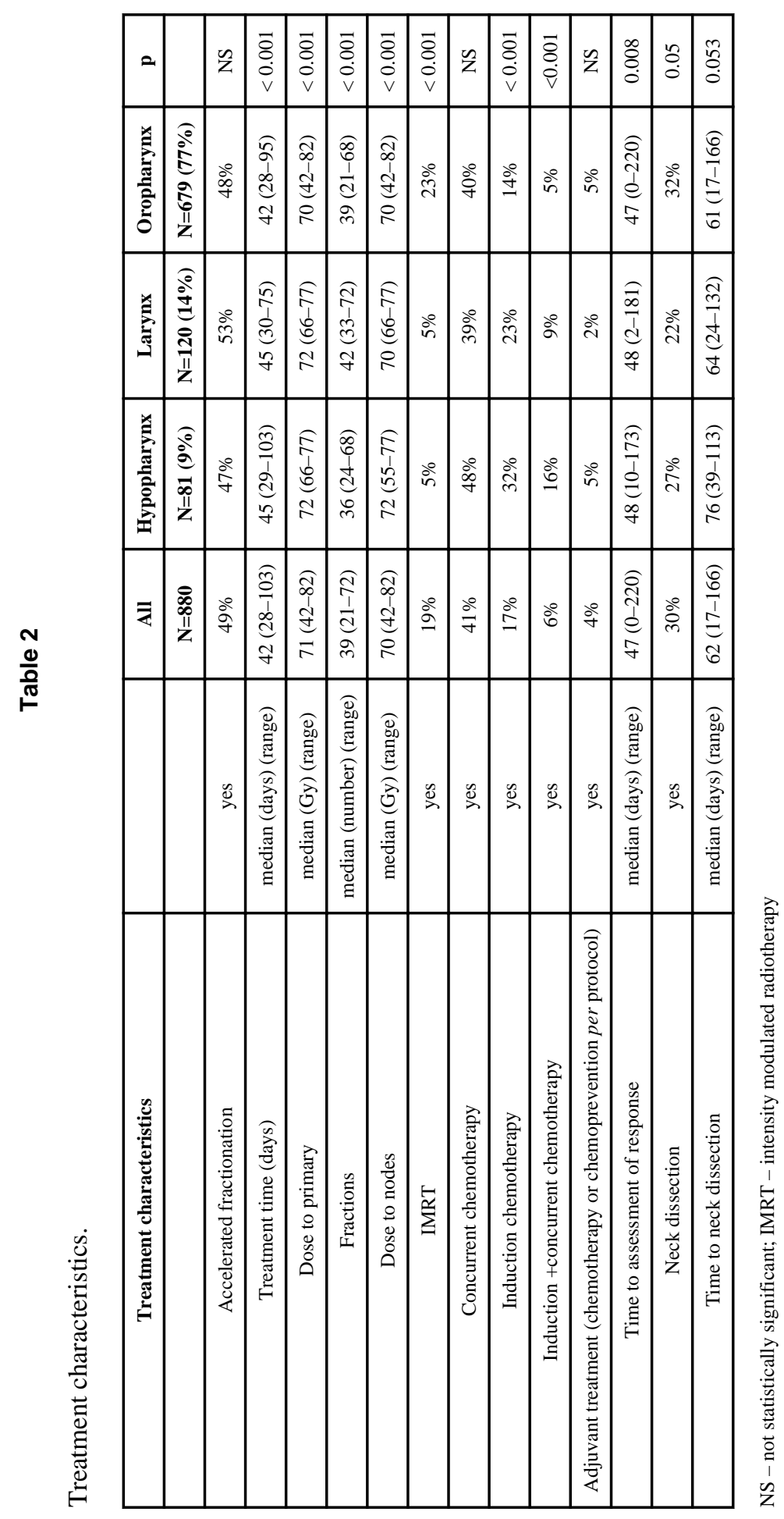


Table 3

Univariate Cox regression Model with Any Neck Failure as Endpoint

\begin{tabular}{|l|c|c|c|c|}
\hline Variable & HR & p- value & \multicolumn{2}{|c|}{$95 \%$ I } \\
\hline T2 & 2.01 & 0.10 & 0.88 & 4.56 \\
\hline T3 & 2.67 & 0.02 & 1.18 & 6.00 \\
\hline T4 & 6.14 & $<0.001$ & 2.71 & 13.92 \\
\hline N3 & 6.36 & $<0.001$ & 3.25 & 12.43 \\
\hline Largest node & 1.22 & $<0.001$ & 1.12 & 1.34 \\
\hline Node size >=6cm & 4.46 & $<0.001$ & 2.70 & 7.37 \\
\hline Node size >3cm & 1.39 & 0.10 & 0.94 & 2.07 \\
\hline Node fixed & 3.28 & $<0.001$ & 1.88 & 5.72 \\
\hline Oropharynx & 0.39 & $<0.001$ & 0.23 & 0.66 \\
\hline 2 or more node levels involved & 1.93 & 0.001 & 1.29 & 2.89 \\
\hline Necrotic nodes & 1.91 & 0.02 & 1.11 & 3.26 \\
\hline Induction chemotherapy & 2.00 & 0.001 & 1.31 & 3.06 \\
\hline Concurrent chemotherapy & 1.67 & 0.01 & 1.14 & 2.44 \\
\hline Treatment time & 1.04 & 0.001 & 1.01 & 1.06 \\
\hline ND Post RT & 0.68 & 0.10 & 0.44 & 1.07 \\
\hline Clinical \& CT PR & 2.68 & $<0.001$ & 1.67 & 4.31 \\
\hline Less than PR & 9.21 & $<0.001$ & 3.80 & 22.32 \\
\hline Response Not CR & 2.29 & $<0.001$ & 1.48 & 3.55 \\
\hline Non-viable tumor in ND & 0.21 & $<0.001$ & 0.09 & 0.47 \\
\hline Largest node post RT & 1.04 & $<0.001$ & 1.03 & 1.06 \\
\hline Post RT node >1.5 \& $<3 \mathrm{~cm}$ & 1.83 & 0.01 & 1.16 & 2.91 \\
\hline Post RT node > 3 cm & 6.86 & $<0.001$ & 3.91 & 12.03 \\
\hline
\end{tabular}

CR - complete response; CT- computed tomography; HR- hazard ratio; ND- neck dissection; RT: radiotherapy; CR - complete response; PR partial response; CT- computed tomography; HR- hazard ratio; ND- neck dissection; RT: radiotherapy 
Table 4

Multivariate Cox regression Model with Any Neck Failure as Endpoint

\begin{tabular}{lcccc}
\hline Variable & HR & p-value & \multicolumn{2}{c}{ 95\% CI } \\
T-Category (T3-4 vs T1-2) & 2.16 & $<0.001$ & 1.44 & 3.22 \\
N-Category (N2 vs N1) & 1.26 & 0.42 & 0.71 & 2.23 \\
N-Category (N3 vs N1) & 3.97 & $<0.001$ & 1.90 & 8.30 \\
Site (Oropharynx vs Other) & 0.47 & $<0.001$ & 0.31 & 0.70 \\
Not CR & 2.61 & $<0.001$ & 1.60 & 4.25 \\
Post RT node $>1.5 \&<3 \mathrm{~cm}$ & 1.98 & 0.009 & 1.19 & 3.29 \\
Post RT node $>3 \mathrm{~cm}$ & 5.34 & $<0.001$ & 2.79 & 10.20 \\
Non-viable tumor in ND & 0.10 & $<0.001$ & 0.04 & 0.23 \\
\hline
\end{tabular}

CR - complete response; HR- hazard ratio; ND- neck dissection; RT: radiotherapy 